\title{
Identification of a novel mutation in the arginine vasopressin-neurophysin II gene affecting the sixth intrachain disulfide bridge of the neurophysin II moiety
}

\author{
Silvana Baglioni, Giovanni Corona ${ }^{1}$, Mario Maggi ${ }^{1}$, Mario Serio $^{2}$ and Alessandro Peri ${ }^{2}$ \\ Medical Genetics, ${ }^{1}$ Andrology and ${ }^{2}$ Endocrine Unit, Department of Clinical Physiopathology, University of Florence, 50139 Florence, Italy \\ (Correspondence should be addressed to A Peri, Endocrine Unit, Department of Clinical Physiopathology, University of Florence, Viale Pieraccini, \\ 6, 50139 Florence, Italy; Email: a.peri@dfc.unifi.it)
}

\begin{abstract}
Objective: Most mutations of the arginine vasopressin-neurophysin II (AVP-NPII) gene cause autosomal dominant familial neurohypophyseal diabetes insipidus (adFNDI). Such mutations are predicted to alter the three-dimensional structure of the prohormone, which accumulates in the cell body, ultimately leading to neuronal degeneration and hormonal deficit. In this study we describe the case of a 26 -year-old female reporting a long-lasting history of polyuria/polydipsia. The father of the patient was affected by diabetes insipidus and was under desmopressin treatment until the time of his death. Nevertheless, the patient had never been subjected to endocrine evaluation. Design and methods: Clinical and genetic studies were performed. An 8-h fluid deprivation test plus desmopressin challenge and a 5\% saline solution test were performed, in order to confirm the diagnosis. DNA was extracted from peripheral blood lymphocytes and subjected to direct sequencing of the entire coding region of the AVP-NPII gene.

Results and conclusions: Clinical assessment of the patient confirmed the diagnosis of neurohypophyseal diabetes insipidus. Desmopressin treatment was started, which effectively reversed the polyuria/ polydipsia syndrome. Genetic analysis revealed a novel mutation $(1665 \mathrm{~T}>\mathrm{A})$ in exon 2 of the AVP-NPII gene, disrupting one of the disulfide bonds present in the NPII moiety which play a fundamental role in determining the proper folding of the molecule. In summary, in the present study we have described a novel mutation of the AVP-NPII gene, which is consistent with the malfolding/toxicity hypothesis underlying the pathogenesis of adFNDI.
\end{abstract}

European Journal of Endocrinology 151 605-611

\section{Introduction}

Autosomal dominant familial neurohypophyseal diabetes insipidus (adFNDI) is a rare disorder characterized by polyuria accompanied by polydipsia, and which is due to a deficient secretion of the antidiuretic hormone arginine vasopressin (AVP) $(1,2)$. In most cases the disease is not present at birth but develops in early childhood. Autopsy studies have demonstrated a selective degeneration of the AVP-producing magnocellular neurons in the supraoptic and paraventricular nuclei of the hypothalamus (3-6). Fifty-four different mutations in the AVP-neurophysin II (AVP-NPII) gene (GenBank accession number M11166), linked to adFNDI, have been identified so far. The majority of the known mutations are located in the coding region of the NPII moiety (i.e. 7-9), whereas only a few mutations localize in the part of the gene encoding the signal peptide (7). Only recently, one mutation affecting the AVP moiety has been described (10). Mutations affecting the AVP-NPII gene are predicted to determine cytotoxic accumulation of the prohormone in the supraoptic and paraventricular nuclei, ultimately leading to neuronal damage. The expression of mutations causing adFNDI in cell models supports this hypothesis, because the mutant AVP prohormone was constantly found to be retained in the endoplasmic reticulum (11-17). More recently, these observations have been confirmed in transgenic animals expressing a mutated AVP-NPII gene (18-20).

The NPII moiety contains seven disulfide bridges, which are covalent bonds formed by the oxidation of two cysteine residues and are essential in determining the three-dimensional structure of the molecule. In particular, disulfide bonds occur between codons 41-85, $44-58, \quad 52-75, \quad 59-65,92-104,98-116$ and 105-110 of the prepro-AVP-NPII sequence. The formation of disulfide bonds occurs during the folding of proteins in the endoplasmic reticulum and their function is to stabilize the structure of proteins. Mutations involving cysteine residues which form disulfide bonds in the NPII protein have been described (one in 
the third bond, one in the fourth, three in the fifth, four in the sixth and three in the seventh) $(16,21-28)$. These mutations are predicted to destabilize the folded protein and allow the formation of abnormal disulfide bridges with some of the other cysteine residues. We describe here the clinical and molecular features of a patient with neurohypophyseal diabetes insipidus, in which a novel mutation $(1665 \mathrm{~T}>\mathrm{A})$, determining a substitution of cysteine at position 98 of the preproAVP-NPII by serine, was identified by direct sequencing.

\section{Subjects and methods}

\section{Subjects}

Studies were performed on the affected patient, as well as on her son, her sister and two paternal aunts who did not report symptoms suggestive for diabetes insipidus. No other living relative of the patient was reported to have polyuria/polydipsia.

\section{Clinical procedures}

A 26-year-old woman was referred to our unit by her family doctor, because of a long-lasting history of polyuria/polydipsia. Her father, dead at the age of 43 secondary to an acute myocardial infarction, was affected by neurohypophyseal diabetes insipidus and was under desmopressin treatment. Nevertheless, the patient had never been evaluated before in relationship to the polyuria/ polydipsia history together with the familial anamnesis of diabetes insipidus. However, the mother remembered her daughter crying a lot as an infant, and the patient reported that, to her memory, she had always been affected by polyuria/polydipsia. An 8-h fluid deprivation test followed by $2 \mu \mathrm{g}$ desmopressin i.m. (DDAVP, Minirin; Ferring Pharmaceuticals Ltd, North York, Ontario, Canada) was performed, as well as a challenge with $5 \%$ saline solution. Plasma levels of prolactin (PRL), growth hormone (GH), insulin-like growth factor-I (IGF-I), follicle-stimulating hormone (FSH), luteinizing hormone (LH), adrenocorticotropin (ACTH), cortisol, thyrotropin (TSH), free thyroxine (fT4), and free triiodothyronine (fT3) were determined. A computed tomography (CT) scan of the brain was performed.

\section{Genetic analysis}

Genomic DNA was extracted from peripheral blood lymphocytes using a standard proteinase $\mathrm{K}$ and phenol-chloroform method. The coding region of the AVP-NPII gene and the exon-intron boundaries were amplified by PCR using the primers and the conditions reported in Table 1 , after a previous denaturation step at $96{ }^{\circ} \mathrm{C}$ for $5 \mathrm{~min}$.

The PCR reactions were performed in a total volume of $100 \mu \mathrm{l}$, using $1 \mu \mathrm{g}$ genomic DNA, $10 \mu \mathrm{M}$ of each primer, $10 \mu \mathrm{M}$ of dNTPs, PCR buffer $(10 \mathrm{mM}$ Tris $-\mathrm{HCl}$, $50 \mathrm{mM} \mathrm{KCl}, 1.5 \mathrm{mM} \mathrm{MgCl} 2,0.01 \%(\mathrm{w} / \mathrm{v})$ gelatin) and 2U Taq polymerase. Because of the high guaninecytosine (GC) content of exon 3, 10\% DMSO was added to the PCR buffer. Amplicons were purified using the QIAquick purification kit (Qiagen, Crawley, W Sussex, UK) and direct sequencing was carried out using the Big Dye Terminator Cycle Sequencing kit (Applied Biosystems (ABI) Warrington, Cheshire, UK), according to the manufacturer's instructions. Sequencing reactions were purified using the DyeEx 2.0 Spin kit (Qiagen) and samples were run on an ABI 310 capillary sequencer (Applied Biosystems).

\section{Modeling}

Three-dimensional modeling of the wild-type and the mutated NPII protein was performed by SWISSMODEL, a fully automated protein structure homologymodeling server (http://www.expasy.org/spdbv/) (29).

\section{Results}

\section{Clinical studies}

The results of the fluid deprivation test and the desmopression test, shown in Table 2, unequivocally indicated that the patient was affected by neurohypophyseal diabetes insipidus. In Fig. 1 the inverse relationship between the urinary volume and the urine osmolality during the fluid deprivation test and after desmopressin administration is shown. In addition, the diagnosis was further confirmed by i.v. infusion of hypertonic (5\%) saline solution $(0.06 \mathrm{ml} / \mathrm{kg} / \mathrm{min})$ (Table 3$)$. The test was stopped after $45 \mathrm{~min}$ (a total volume of $170 \mathrm{ml}$

Table 1 PCR conditions and primers sequences for the AVP gene. All the PCR reactions were preceded by a denaturation step at $96^{\circ} \mathrm{C}$ for $5 \mathrm{sec}$.

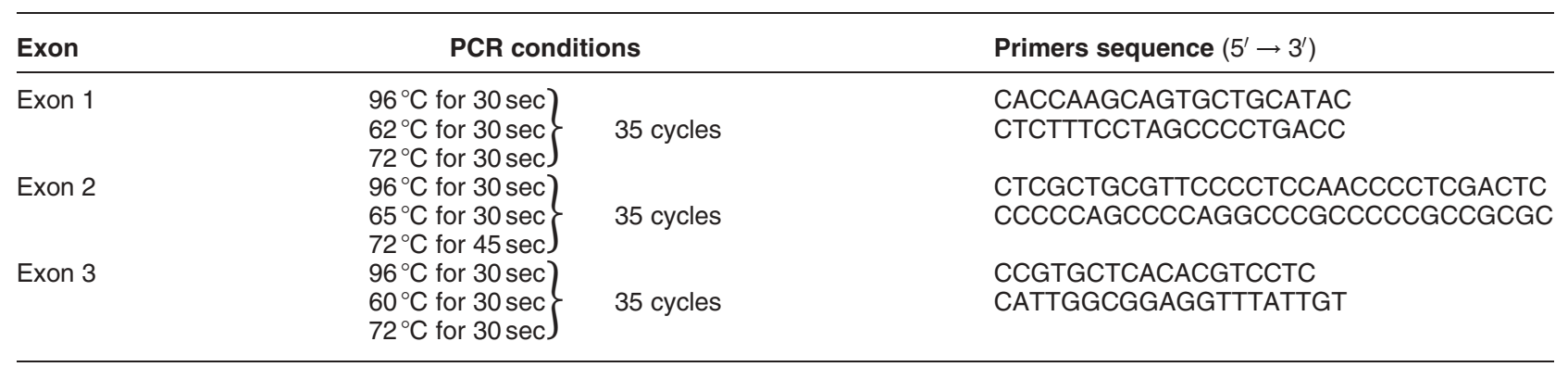


Table 2 Results of the fluid deprivation test plus DDAVP test.

\begin{tabular}{|c|c|c|c|c|c|c|}
\hline \multirow[b]{2}{*}{ Time (h) } & \multirow[b]{2}{*}{ Weight (kg) } & \multirow{2}{*}{$\begin{array}{c}\text { Plasma osmolality } \\
(\mathrm{mosm} / \mathrm{kg})\end{array}$} & \multirow[b]{2}{*}{ Time (h) } & \multicolumn{2}{|c|}{ Urine } & \multirow{2}{*}{$\begin{array}{l}\text { Urine osmolality } \\
\qquad(\mathrm{mosm} / \mathrm{kg})\end{array}$} \\
\hline & & & & Volume $(\mathrm{ml} / \mathrm{h})$ & Density & \\
\hline 0700 & 63 & 279 & $2400-0700$ & 270 & 1004 & 103 \\
\hline 0800 & 62.5 & 277 & 0700-0800 & 310 & 1003 & 84 \\
\hline 0900 & 62.1 & - & 0800-0900 & 310 & 1002 & 83 \\
\hline 1000 & 61.8 & 286 & $0900-1000$ & 310 & 1001 & 87 \\
\hline 1100 & 61.5 & 288 & $1000-1100$ & 310 & 1001 & 98 \\
\hline 1200 & 61 & 316 & $1100-1200$ & 255 & 1002 & 135 \\
\hline 1300 & 60.8 & 290 & $1200-1300$ & 155 & 1003 & 171 \\
\hline 1400 & 60.7 & 289 & $1300-1400$ & 114 & 1003 & 220 \\
\hline 1500 & 60.6 & 287 & $1400-1500$ & 127 & 1002 & 196 \\
\hline \multicolumn{7}{|c|}{ DDAVP injection } \\
\hline 1800 & 61.9 & 284 & $1500-1800$ & 8.6 & 1014 & 441 \\
\hline 2000 & 62.6 & 281 & $1800-2000$ & 52.5 & 1010 & 476 \\
\hline 0300 & 62.8 & 276 & $2000-0300$ & 20.85 & 1012 & 563 \\
\hline
\end{tabular}

was administered), because of vomiting. However, the marked increase in plasma osmolality together with unmeasurably low AVP levels fully confirmed the diagnosis. Plasma levels of PRL, GH, IGF-I, FSH, LH, ACTH, cortisol, TSH, fT4 and fT3 were within the normal range and a CT scan of the brain did not reveal any pathological findings. DDAVP treatment was started and polyuria/polydipsia were satisfactorily controlled using $0.2 \mathrm{mg}$ orally twice a day.

\section{Genetic analysis}

The pedigree of the family is shown in Fig. 2. Sequence analysis of the entire AVP-NPII coding region in the patient revealed the presence of a heterozygous transversion mutation of a thymidine to adenine at nucleotide 1665 (1665T $>$ A) in exon 2 (Fig. 3A). This mutation alters codon 98 of the prepro-AVPNPII sequence, corresponding to codon 67 of the NPII moiety, from TGC to AGC, substituting serine for cysteine (C98S). This mutation disrupts the disulfide bond normally linking C98 with C116. No other mutation was detected in exon 2 , or in exon 1 or 3 . Because of the previous death of the father of the patient, who was the only member of the family known to be affected by diabetes insipidus, further sequencing was restricted to unaffected relatives (the 1-year-old son of the patient, her sister and two paternal aunts). In no case was the $1665 \mathrm{~T}>\mathrm{A}$ mutation (Fig. 3B) or any other mutation in the coding region of the AVP-NPII gene detected. The effect of the C98S mutation on the predicted

$\square$ Diuresis

$\Delta$ Urinary osmolality

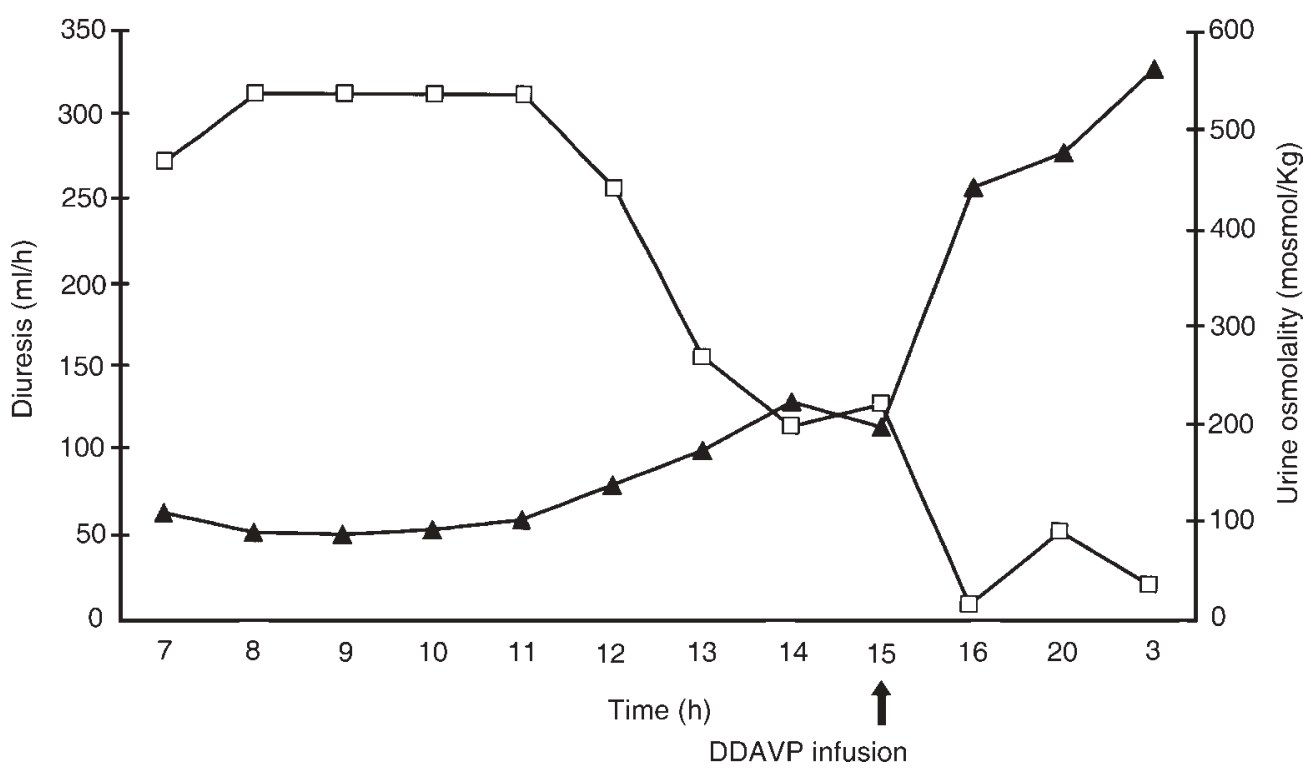

Figure 1 Relationship between diuresis and urinary osmolality during the fluid deprivation test plus DDAVP test. 
Table 3 Results of the saline hypertonic infusion test.

\begin{tabular}{lcccc}
\hline & & \multicolumn{3}{c}{ Plasma } \\
\cline { 3 - 5 } $\begin{array}{l}\text { Time } \\
(\mathrm{h})\end{array}$ & $\begin{array}{c}\text { Weight } \\
(\mathrm{kg})\end{array}$ & $\begin{array}{c}\text { BP } \\
(\mathrm{mmHg})\end{array}$ & $\begin{array}{c}\text { Osmolality } \\
(\mathrm{mosm} / \mathrm{kg})\end{array}$ & $\begin{array}{c}\text { AVP } \\
(\mathrm{ng} / 1)\end{array}$ \\
\hline 0 & 54 & $110 / 80$ & 280 & $<1$ \\
+30 min & 62.5 & - & 299 & $<1$ \\
+45 min & 62.1 & $115 / 70$ & 299 & $<1$ \\
\hline
\end{tabular}

$\mathrm{BP}$, blood pressure.

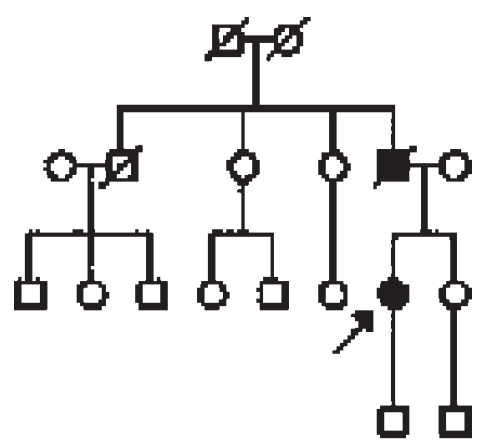

Figure 2 Family pedigree. The arrow indicates the carrier of the $1665 \mathrm{~T}>\mathrm{A}$ mutation. The black symbols indicate the family members affected by diabetes insipidus.

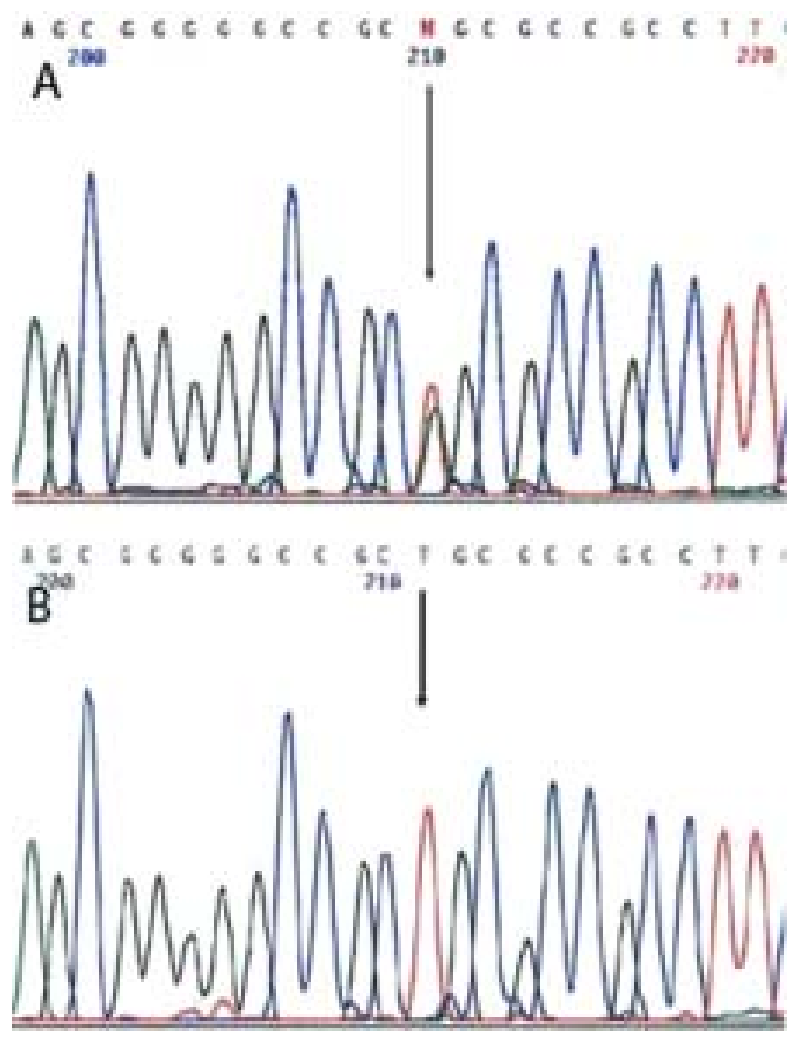

Figure 3 Automated sequencing of the AVP-NPII gene. A portion of exon 2, in which the novel mutation was identified, is represented. (A) The 1665T > A mutation in one allele of the AVP-NPII gene of the affected patient is indicated by the arrow and $(B)$ the nucleotide substitution was not present in the son of the patient (arrow). structure of the NPII protein was evaluated by the SWISS-MODEL server (see section on Modeling). A schematic representation of the three-dimensional structure of the mutated vs the wild-type protein is shown in Fig. 4A and B respectively.

\section{Discussion}

This study describes a case of neurohypophyseal diabetes insipidus due to a novel mutation in the
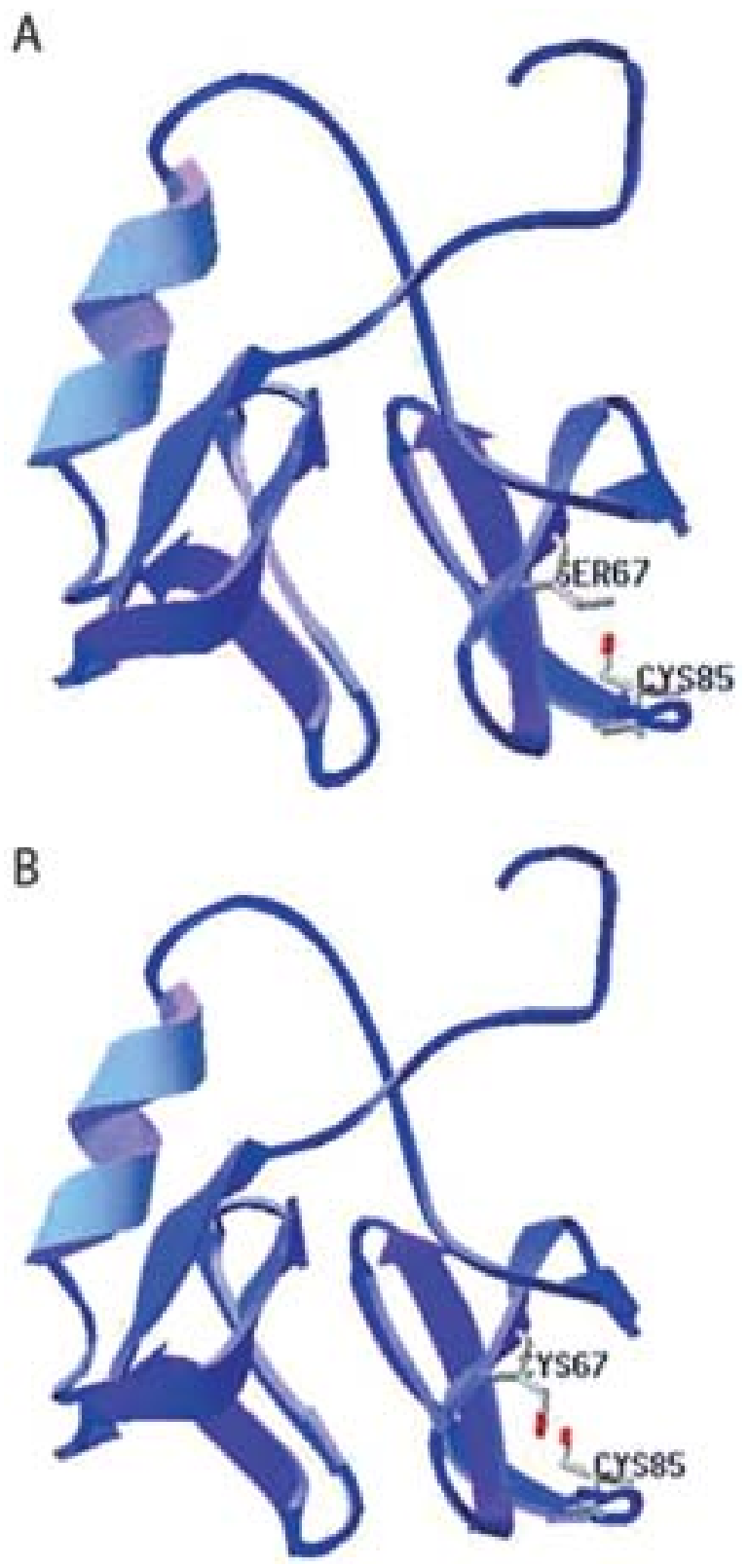

Figure 4 Three-dimensional structure of the (A) mutated and (B) the wild-type NPII, as derived by the SWISS-MODEL server (29) (see also www.expasy.org/spdbv/). 
AVP-NPII gene. Although the father of the patient was dead by the time she came to our attention at the age of 26 years, the genetic transmission of the disease is strongly suggested by the fact that he was also affected by diabetes insipidus and was treated with desmopressin throughout his life. Based on the long-lasting history of polyuria/polydipsia of the patient, clinical assessment to evaluate the AVP reserve was performed; this confirmed the diagnosis of diabetes insipidus. Genetic analysis revealed that the patient was heterozygous for the missense mutation $1665 \mathrm{~T}>\mathrm{A}$ encoding the amino acid substitution C98S. This newly described mutation is located in exon 2 of the AVP-NPII gene, which encodes part of the NPII moiety. It affects the sixth of the seven disulfide bonds present in the NPII protein, linking C98 to C116. Two other mutations involving C98 have been described previously. In one case a stop codon was introduced, determining the formation of a truncated protein (24), whereas in the other case the missense mutation $1665 \mathrm{~T}>\mathrm{G}$ determined the amino acid substitution C98G (25). Two other missense mutations affecting the C116 residue, thus disrupting the same disulfide bond, have been described (28). Furthermore, eight mutations involving the other disulfide bonds in the NPII protein have been described $(16,21-23,26,27)$. Therefore, in a total of 55 (included the novel mutation we have described) different mutations in the AVP-NPII gene described so far, almost one-fourth affected one of the seven disulfide bonds present in NPII; these are important in determining its tertiary structure. If only the mutations affecting the NPII moiety are taken into account (a total of 45), the proportion of those affecting cysteine residues which form disulfide bonds rises close to $30 \%$.

This pattern of mutations is very interesting, because it suggests that abnormal folding and selfassociation of the AVP-NPII precursor may be a common pathogenic mechanism in adFNDI. The misfolding hypopthesis predicts a series of abnormalities that could explain the main clinical features of the disease. Similarly to other newly synthesized proteins destined for further processing and secretion $(30,31)$, pro-AVP-NPII must fold and self-associate correctly in the endoplasmic reticulum before it can be directed to the Golgi apparatus and secretory vesicles for further processing and storage (32). The misfolded protein is retained in the endoplasmic reticulum, thus accumulating and eventually destroying the cell (11-17). Alternatively, a structurally abnormal protein may bind to chaperones $(33,34)$ and undergo proteolytic degradation (35). The progressive cell loss in adFNDI is in agreement with the dominance of the mutation as a consequence of a dominant negative mechanism, with the delayed onset of the clinical signs of the AVP deficiency, characteristic of these patients, as well as with the autopsy finding of degeneration of magnocellular neurons $(3-6)$.
The accumulation of a structurally abnormal pro-AVP-NPII in the endoplasmic reticulum has been beautifully demonstrated in the past few years in animal models of adFNDI (18-20). Among the four transgene models of naturally occurring human mutations causing adFNDI generated so far, the C98stop mutation was targeted in three cases $(18-20)$, whereas in the remaining case the AVP signal sequence was mutated $[\mathrm{A}(-1) \mathrm{T}](20)$. The C98stop mutation determined an early onset of diabetes insipidus and a markedly worse phenotype in mice than the $[\mathrm{A}(-1) \mathrm{T}]$ mutation (20), similarly to that which occurs in humans. The mutated protein accumulated in the endoplasmic reticulum as autophagic vesicles targeted for lysosomal degradation (18, 19). This phenomenon appears to be substantiated by the observed overexpression of immunoglobulin heavy chain binding protein $(\mathrm{BiP})$, a member of the heat-shock proteins 70 (HSP70) family of molecular chaperones, which binds avidly to misfolded proteins accumulated in the endoplasmic reticulum (20). Eventually, the autophagic vesicles might also trap the wild-type protein by aberrant disulfide bond interactions with the mutant protein. The 'autophagy hypothesis' does not exclude the possibility that neuronal atrophy might ensue with the progession of time. In fact, loss of AVP-producing neurons was found in mutant animals (20). Besides the C98stop mutation, the C98G substitution was also found to determine a very early onset of diabetes insipidus in an affected family (25), thus further suggesting that the C98 plays a critical role in the proper pro-AVP-NPII folding and that substitutions at this amino acid residue may be particularly deleterious and lead to rapid accumulation of misprocessed precursor. In the case we have described here the exact age of onset of the disease of the patient could not be ascertained, because of the poor compliance of the patient as well as of her relatives. Surprisingly enough, considering the presence of diabetes insipidus in her family, she came to medical attention only at the age of 26 . Nevertheless, as far as she could remember, she had 'always' been affected by polyuria and polydipsia. In addition, her mother well remembered her daughter crying a lot when she was an infant, possibly suggesting a dehydration status. Therefore, in agreement with previous observations, apparently also in this case was a mutation involving the C98 of the prepro-AVP-NPII molecule associated with a precocious onset of diabetes insipidus.

In conclusion, in the present study we have described a case of FNDI due to a novel missense mutation disrupting the sixth disulfide bond in the AVP-NPII precursor protein. This mutation enlarges the group of genetic abnormalities in the AVP-NPII gene involving a cysteine residue and underlines the fundamental role of disulfide bonds in maintaining the structural and functional integrity of the molecule. 


\section{References}

1 Robertson GL. Diabetes insipidus. Endocrinology and Metabolism Clinics of North America 199524 549-572.

2 Maghnie M, Cosi G, Genovese E, Manca-Bitti ML, Cohen A, Zecca S, Tinelli C, Gallucci M, Bernasconi S, Boscherini B, Severi F \& Arico M. Central diabetes insipidus in children and young adults. New England Journal of Medicine $20003 \mathbf{3 4 3}$ 998-1007.

3 Braverman LE, Mancini JP \& McGoldrick DM. Hereditary idiopathic diabetes insipidus. A case report with autopsy findings. Annals of International Medicine 196563 503-508.

4 Green JR, Buchan GC, Alvord ECJ \& Swanson AG. Hereditary and idiopathic types of diabetes insipidus. Brain 196790 707-714.

5 Bergeron C, Kovacs K, Ezrin C \& Mizzen C. Hereditary diabetes insipidus: an immunohistochemical study of the hypothalamus and pituitary gland. Acta Neuropathologica 1991 $81345-348$

6 Mahoney CP, Weinberger E, Bryant C, Ito M, Jameson JL \& Ito M. Effects of aging on vasopressin production in a kindred with autosomal dominant neurohypophyseal diabetes insipidus due to the DeltaE47 neurophysin mutation. Journal of Clinical Endocrinology and Metabolism 200287 870-876.

7 Christensen JH, Siggaard C, Corydon TJ, deSanctis L, Kovacs L, Robertson GL, Gregersen N \& Rittig S. Six novel mutations in the arginine vasopressin gene in 15 kindreds with autosomal dominant familial neurohypophyseal diabetes insipidus give further insight into the pathogenesis. European Journal of Human Genetics $20041244-51$.

8 Elias PC, Elias LL, Torres N, Moreira AC, Antunes-Rodrigues J \& Castro M. Progressive decline of vasopressin secretion in familial autosomal dominant neurohypophyseal diabetes insipidus presenting a novel mutation in the vasopressin-neurophysin II gene. Clinical Endocrinology $200359511-518$.

9 Rutishauser J, Kopp P, Gaskill MB, Kotlar TJ \& Robertson GL. A novel mutation (R97C) in the neurophysin moiety of preprovasopressin-neurophysin II associated with autosomal-dominant neurohypophyseal diabetes insipidus. Molecular Genetics and Metabolism 199967 89-92.

10 Rittig S, Siggaard C, Ozata M, Yetkin I, Gregersen N, Pedersen EB \& Robertson GL. Autosomal dominant neurohypophyseal diabetes insipidus due to substitution of histidine for tyrosine (2) in the vasopressin moiety of the hormone precursor. Journal of Clinical Endocrinology and Metabolism $2002873351-3355$.

11 Olias G, Richter D \& Schmale H. Heterologous expression of human vasopressin-neurophysin precursors in a pituitary cell line: defective transport of a mutant protein from patients with familial diabetes insipidus. DNA and Cell Biology 199615 929-935.

12 Ito M \& Jameson JL. Molecular basis of autosomal dominant neurohypophyseal diabetes insipidus. Cellular toxicity caused by the accumulation of mutant vasopressin precursors within the endoplasmic reticulum. Journal of Clinical Investigation 199799 1897-1905.

13 Beuret N, Rutishauser J, Bider MD \& Spiess M. Mechanism of endoplasmic reticulum retention of mutant vasopressin precursor caused by a signal peptide truncation associated with diabetes insipidus. Journal of Biological Chemistry $1999 \mathbf{2 7 4}$ 18965-18972.

14 Nijenhuis M, Zalm R \& Burbach JP. Mutations in the vasopressin prohormone involved in diabetes insipidus impair endoplasmic reticulum export but not sorting. Journal of Biological Chemistry $199927421200-21208$.

15 Nijenhuis M, Zalm R \& Burbach JP. A diabetes insipidus vasopressin prohormone altered outside the central core of neurophysin accumulates in the endoplasmic reticulum. Molecular and Cellular Endocrinology 2000167 55-67.

16 Nijenhuis M, van den Akker EL, Zalm R, Franken AA, Abbes AP, Engel H, de Wied D \& Burbach JP. Familial neurohypophyseal diabetes insipidus in a large Dutch kindred: effect of the onset of diabetes on growth in children and cell biological defects of the mutant vasopressin prohormone. Journal of Clinical Endocrinology and Metabolism 200186 3410-3420.

17 Siggaard C, Rittig S, Corydon TJ, Andreasen PH, Jensen TG, Andresen BS, Robertson GL, Gregersen N, Bolund L \& Pedersen EB. Clinical and molecular evidence of abnormal processing and trafficking of the vasopressin preprohormone in a large kindred with familial neurohypophyseal diabetes insipidus due to a signal peptide mutation. Journal of Clinical Endocrinology and Metabolism 199984 2933-2941.

18 Si-Hoe S, de Bree FM, Nijenhuis M, Davies JE, Howell LM, Tinley H, Waller SJ, Zeng Q, Zalm R, Sonnemans M, Van Leeuwen FW. Burbach JP \& Murphy D. Endoplasmic reticulum derangement in hypothalamic neurons of rats expressing a familial neurohypophyseal diabetes insipidus mutant vasopressin transgene. FASEB Journal 200014 1680-1684.

19 Davies J \& Murphy D. Autophagy in hypothalamic neurones of rats expressing a familial neurohypophyseal diabetes insipidus transgene. Journal of Neuroendocrinology 2002 14 629-637.

20 Russell TA, Ito M, Ito M, Yu RN, Martinson FA, Weiss J \& Jameson LJ. A murine model of autosomal dominant neurohypophyseal diabetes insipidus reveals progressive loss of vasopressinproducing neurons. Journal of Clinical Investigation 2003112 1697-1706.

21 Rittig S, Robertson GL, Siggaard C, Kovacs L, Gregersen N, Nyborg J \& Pedersen EB. Identification of 13 new mutations in the vasopressin-neurophysin II gene in 17 kindreds with familial autosomal dominant neurohypophyseal diabetes insipidus. American Journal of Human Genetics $1996 \mathbf{5 8}$ 107-117.

22 Skordis N, Patsalis PC, Hettinger JA, Kontou M, Herakleous E, Krishnamani MR \& Phillips JA 3rd. A novel arginine vasopressin-neurophysin II mutation causes autosomal dominant neurohypophyseal diabetes insipidus and morphologic pituitary changes. Hormone Research 200053 239-245.

23 Grant FD, Ahmadi A, Hosley CM \& Majzoub JA. Two novel mutations of the vasopressin gene associated with familial diabetes insipidus and identification of an asymptomatic carrier infant. Journal of Clinical Endocrinology and Metabolism $1998 \mathbf{8 3}$ 3958-3964.

24 Nagasaki H, Ito M, Yuasa H, Saito H, Fukase M, Hamada K, Ishikawa E, Katakami H \& Oiso Y. Two novel mutations in the coding region for neurophysin-II associated with familial central diabetes insipidus. Journal of Clinical Endocrinology and Metabolism $1995801352-1356$.

25 DiMeglio LA, Gagliardi PC, Browning JE, Quigley CA \& Repaske DR. A missense mutation encoding cys $(67) \rightarrow$ gly in neurophysin II is associated with early onset autosomal dominant neurohypophyseal diabetes insipidus. Molecular Genetics and Metabolism 200172 39-44.

26 Rutishauser J, Kopp P, Gaskill MB, Kotlar TJ \& Robertson GL. Clinical and molecular analysis of three families with autosomal dominant neurohypophyseal diabetes insipidus associated with a novel and recurrent mutations in the vasopressin-neurophysin II gene. European Journal of Endocrinology $2002 \mathbf{1 4 6}$ 649-656.

27 Fujii H, Iida S \& Moriwaki K. Familial neurohypophyseal diabetes insipidus associated with a novel mutation in the vasopressinneurophysin II gene. International Journal of Molecular Medicine 20005 229-234.

28 Abbes AP, Bruggeman B, van Den Akker EL, de Groot MR, Franken AA, Drexhage VR \& Engel H. Identification of two distinct mutations at the same nucleotide position, concomitantly with a novel polymorphism in the vasopressin-neurophysin II gene (AVP-NP II) in two Dutch families with familial neurohypophyseal diabetes insipidus. Clinical Chemistry $2000 \mathbf{4 6}$ 1699-1702.

29 Guex N \& Peitsch MC. SWISS-MODEL and the Swiss-Pdb Viewer: an environment for comparative protein modeling. Electrophoresis $1997182714-2723$. 
30 Helenius A, Marquardt T \& Braakman I. The endoplasmic reticulum as a protein-folding compartment. Trends in Cell Biology $19922227-231$.

31 Gaut JR \& Hendershot LM. The modification and assembly of proteins in the endoplasmic reticulum. Current Opinion in Cell Biology 19935 589-595.

32 Halban PA \& Irminger J-C. Sorting and processing of secretory proteins. Biochemical Journal $19942991-18$.

33 Rutherford SL \& Zucker CS. Protein folding and the regulation of signaling pathways. Cell 199479 1129-1132.
34 Becker J \& Craig EA. Heat-shock proteins as molecular chaperones. European Journal of Biochemistry 1994219 11-23.

35 Urade R \& Kito M. Inhibition by acidic phospholipids of protein degradation by ER-60 protease, a novel cysteine protease, of endoplasmic reticulum. FEBS Letters 1992312 83-86.
Received 21 May 2004

Accepted 30 July 2004 